\title{
Reseña de Lo divino y lo humano: poetas místicos de India y de España en la modernidad temprana, ed. Meenakshi Sundriyal y Juan Manuel Escudero Baztán, New Delhi/Pamplona, CSPILAS- Jawaharlal Nehru University/GRISO- Universidad de Navarra (Friends Digital Color Solutions), 2017, 168 pp., ISBN 181-901849-9-7
}

\section{Sabyasachi Mishra}

Amity University Rajasthan

INDIA

smishra@jpr.amity.edu

[Hipogrifo, (issn: 2328-1308), 6.1, 2018, pp. 729-733]

Recibido: 16-03-2018 / Aceptado: 09-05-2018

DOI: http://dx.doi.org/10.13035/H.2018.06.01.51

Con la publicación del libro Lo divino y lo humano: poetas místicos de India y de España en la modernidad temprana/The Divine and the Human: Early Modern Mystic: Poets of India and Spain, GRISO y CSIPLAS han mostrado una vez más su colaboración en el estudio de distintos aspectos del Siglo de Oro. Las diversas contribuciones contenidas en este libro investigan diversos aspectos relacionados con el concepto del misticismo y analizan varios temas presentes en las obras de poetas místicos, santos y sacerdotes, indios, españoles y persas. Y varios de los investigadores que publican en este libro hablan de la necesidad de seguir investigando, con perspectiva comparatista India/España, la producción de varios pensadores del misticismo de los siglos XVI y XVII.

Por su parte, los editores del volumen señalan que el concepto de misticismo está presente en todas las culturas y religiones del mundo y hacen notar que existe una gran similitud en la presentación de los pensamientos de varios escritores indios y españoles. No es solo que el santo, en ocasiones, viva ese instante místico, sino que en sus obras muestra ese gran momento de inspiración divina y los lec- 
tores, que a la vez son escritores, también pueden divulgar ese mensaje del pensamiento divino.

El libro comienza con una introducción crítica de este fenómeno en dos espacios geográficos, el indio y el español, y nos introduce en varios subtemas que son necesarios para comprender el concepto del misticismo. Luego, en el primer capítulo, «Lalan Fakir: El místico Bengalí en busca del ser del alma», la investigadora Anindita Roy habla de la doctrina de Baul, que en sí misma es una mezcla de tres doctrinas humanistas, principalmente el sufismo, que proviene de Persia, el Vaishnavismo, del hinduismo y la doctrina Sahajiya del budismo. Como un mendicante, el cantautor Lalan Faquir presenta la igualdad de las tres religiones en sus cantos, y el trabajo explica cómo dio forma de este pensamiento.

En el segundo capítulo, «Divine Divinity and Devotion: Configuring Knowledge and Experienece in the Artistry of Mirabai, St. John of the Cross and St. Teresa of Ávila», Bhavatosh IndraGuru habla de los pensamientos de Mirabai, de San Juan y de Santa Teresa. Al principio el profesor habla de cómo el ego constituye un obstáculo para el desarrollo de los distintos pensamientos de estos autores. Después analiza en profundidad los pensamientos de Mirabai. Para los lectores que desconozcan el misticismo indio, conviene recordar que Mirabai fue una importante poeta y devota del siglo XVI en la India, y según ella, como nos presenta el investigador, se puede sentir al Supremo a través de distintos órganos, de forma que este Él nos guía y nos ayuda. Y hay que comportarse bien para que Él siempre pueda venir a ayudarnos y guiarnos. La poeta, a través de sus escrituras, humaniza a la Divinidad.

Otro capítulo interesante es el del investigador Carlos Agulló, «Entre los pucheros anda el Señor», donde se nos habla de los problemas que sufre un lector que no sabe español -o incluso un traductor - cuando lee distintos poemas de Santa Teresa y no traduce bien su poesía. A través de distintos ejemplos (por ejemplo: «Entre los pucheros anda el Señor», «Sólo Dios basta», «Vuestra soy, para Vos nací», «¿Qué queréis, Señor, de mí?»), el investigador conocido internacionalmente en este tema, nos habla de la necesidad de una buena traducción de la poesía mística. Siguiendo el mismo tema de misticismo, en su artículo, «El oxímoron: telar de los "instantes eternos" en el lenguaje de la mística, una aproximación a esta figura retórica en la literatura espiritual castellana» el profesor Carlos Varona Narvión empieza explicando el tema oxímoron con las palabras opuestas por ejemplo dolor y placer, y explica que el lenguaje de la mística es una unión de las palabras que son ordinarias como "Marriage of Heaven and Hell" como las palabras asiáticas "salsaagridulce, crecimiento negativo, realidad virtual" etc. Esa unión nace de las experiencias intensas que solamente podría estar explicadas por esa categoría de las palabras. Luego el autor de ese artículo nos presenta algunos ejemplos de oxímoron en San Juan de la Cruz, cual es la música callada, la soledad sonora. Según el autor de este artículo, Santa Teresa, también ha utilizado a menudo la paradoja en sus escritos que es muy cerca del oxímoron y acaba con algunos poemas de esa poeta mística.

El libro que reseño abarca no solo temas relacionados con el hinduismo y el cristianismo, sino que incluye además temas islámicos como el antes mencionado de la doctrina de Baul; asimismo, se nos habla aquí también de la biografía y del 
pensamiento de otro santo musulmán que defiende la supremacía de Alá y habla el misticismo islámico. Se llamaba Hamid Bin Fazl Allah, conocido como Shaikh Jamali, que creía en la secta sufí del islam y era también un hagiógrafo importante de Delhi, la actual capital de la India. Según el profesor Gulfishan Khan, la ciudad DeIhi le debe mucho, porque merced a sus poemas místicos los emperadores Babur y Humayun, de la dinastía mogol, construyeron aquí distintos lugares para rezar, porque les influjo mucho a través de su poesía. Cabe destacar que tenía un puesto superior en la administración mogol, así tuvo éxito en traer a Delhi distintos pensadores y representantes de arte islámico y les rogó que los emperadores mogoles ayudaran en la construcción de una parte de la ciudad.

Siguiendo el hilo del misticismo, pero desde una perspectiva femenina, la profesora Java Singh, en su artículo «The Feminine Difference in the Poetry of Santa Teresa and Saint Mirabai», se centra en los textos y las vidas de ambas devotas y/o autoras, Santa Teresa y Mirabai, que siguen siendo importantes e influyentes para los lectores actuales. La estudiosa explica con varios ejemplos que la voz de Mirabai no es una voz simplemente femenina, sino que es expresión de los devotos, sea cual sea su sexo; y su vulnerabilidad es la misma cualquiera que sea su casta y/o región. Por otro lado, Santa Teresa en sus pensamientos muestra el uso subversivo de la lengua a través de la utilización del léxico femenino (por ejemplo, Ilanto, herida, temor, abatimiento...) y muestra las calidades que le da el poder para la asimilación con el divino. Ambas poetas utilizan las herramientas conocidas a personas desconocidas para mostrar la unión con la divinidad. Para mostrar las diferencias entre las dos, la estudiosa nos presenta ejemplos de Maya (Ilusión), el pensamiento femenino, autoconocimiento.

El profesor Juan Manuel Escudero Baztán, en su artículo «Calderón y el diseño del laberinto sacramental», presenta el panorama textual de El laberinto del mundo, que es bastante complejo, como sucede con muchos otros autos sacramentales calderonianos. Ofrece muchos detalles sobre las posibles fechas en que el autor escribió la obra y explica con acierto la estructura de la pieza y el uso de la alegoría. Nos habla igualmente de los distintos mitos griegos presentes en la obra y de cómo el dramaturgo los elabora. En otra contribución, la profesora Maite Teresa Miramón desarrolla el tema de las lágrimas de la Magdalena en Malón de Echaide, explicando el planteamiento místico de esas lágrimas a través de las Sagradas Escrituras. La investigadora demuestra que el escritor Malón de Echaide menciona las distintas potencias del alma para el encuentro que asocia con la divinidad.

El investigador Pawan Kumar, en su artículo «Mysticism, Perfection and Creative Articulation: A Comparative Study of the Mystic Poetry of Mirabai and Kabir and St. Teresa of Avila's The Way to Perfection», habla de cómo los distintos autores sienten y presentan por medio de sus escrituras la experiencia mística. A través de poemas de Kabir, el autor nos muestra la articulación de distintos conocimientos recibidos a partir de las experiencias místicas. Tras la presentación de conocimientos de Kabir, el investigador los relaciona con los mismos conocimientos que recibió Santa Teresa, y explica cómo Santa Teresa los presenta con sus propias palabras. 
El artículo analiza también cómo ambos autores nos presentan el concepto de Dios a través de sus poemas.

En otro capítulo, el traductor del español al hindi Sabyasachi Mishra habla sobre la peregrinación como una experiencia mística en las culturas india y española, y comenta cómo Miguel de Cervantes usa este concepto clave en su obra Persiles y Sigismunda. En el mismo sentido, Kabir, Guru Nanak y algunos otros poetas místicos indios han hablado de la necesidad de viajar y conocerse a sí mismo.

La profesora Saptaparna Roy toca el tema del misticismo y la vida mística y la poesía de la devota Mirabai en su artículo «The Mystical Mira and the Language of her Love». Nos presenta el misticismo de Mirabai, insistiendo en que es una gran crítica femenina de la religión. La autora utiliza un gran número de poemas de Mirabai para descifrar su lenguaje, en el que presenta su amor hacia el dios Krishna, que es un representante de todo lo bello, siendo ella como una criada de este gran Señor. En su artículo «Mysticism and Ontologism in Mirabai and John of The Cross», la profesora Smita Jha prosigue con el mismo tema y habla de temas parecidos, pero en este caso es a través de las escrituras de San Juan de la Cruz como nos presenta el misticismo y se explica la forma en que Dios purifica el alma. Comenta que este pensamiento también se presenta en las escrituras de Mirabai. Opina que el lenguaje y estilo de San Juan ha influido notablemente en la literatura española, en especial en muchos autores místicos.

La investigadora Shrenya Malik nos muestra en su artículo «Las moradas: The Power Equations Underlying Mysticism in the Text of Santa Teresa» cómo la tradición mística española constituye un ejemplo de subversión social y literaria contra las estructuras hegemónicas de su época. El artículo empieza presentando la historia de la época, y como se ha utilizado la metáfora de la morada para describir los cambios en los pensamientos que iban sumergiéndose en el arte cristiano contemporáneo de Santa Teresa. La investigadora habla de la necesidad de descifrar distintas metáforas que están presentes en esta obra de Santa Teresa. Enfatiza que la tradición mística de Santa Teresa y otros pensadores místicos ayudaron a Cervantes para la creación de don Quijote. Por su parte, la profesora Swagata Kumar Basu, en su trabajo «Quijotismo in Santa Teresa and Mysticism from Modern Perspective», sigue dentro del tema de misticismo y, a través de distintos pensamientos de Miguel de Unamuno, intenta descifrar la presencia del quijotismo en Santa Teresa. La investigadora nos presenta cómo recibe Unamuno el concepto de misticismo en el contexto de su época contemporánea y cómo se trata este tema en Del sentimiento trágico de la vida (el quijotismo no es nada más que espiritualismo; según Unamuno, don Quijote es un héroe). En la conclusión se señala que misticismo y quijotismo son los dos productos españoles más importantes, y que ser moderno no significa ser ateo.

La profesora Vinita Jha, en su artículo «Meerabai, The Eternal Bride: A Blend Of Feminine Sensibility And Divine Perception», nos presenta la historia y la tradición del misticismo en la India. Explica, en concreto, que el movimiento místico, conocido también como Bhakti Movement en la literatura y la historia indias, supuso una oportunidad para la emancipación femenina. Antes de este movimiento, las 
mujeres estaban sometidas a la tradición del honor social y los rituales ortodoxos hindúes. La investigadora señala que durante el final de la época medieval india no había ninguna organización femenina para su emancipación y, en este momento, este movimiento unificó a las mujeres en una organización social a través de su devoción. Nos presenta los poemas de algunas poetas y destaca que, a través de ellos, se aprecia que existe el tema de la conciencia de sí misma y hay asimismo una reacción contra el sistema patriarcal y la religión ortodoxa; luego, comentando algunos textos de la poesía de Mirabai, la profesora nos habla de la realidad femenina que estaba presente en la época contemporánea.

En definitiva, se recomienda este libro a los investigadores especializados en la materia, y en general a todas aquellas personas que estén interesadas en conocer algo acerca del misticismo indio y/o español y en estudiar cómo este proceso ha influido en el pensamiento de otros escritores que han leído las obras de distintos autores, importantes, de la India y de España. A través de los distintos capítulos que forman el volumen, los especialistas analizan muy variados temas, pero siempre relacionados con el misticismo indio y/o español. 